\title{
THE CONVERGENCE OF MEAN VALUE ITERATION FOR A FAMILY OF MAPS
}

\author{
B. E. RHOADES AND ŞTEFAN M. ŞOLTUZ
}

Received 3 January 2005 and in revised form 6 September 2005

We consider a mean value iteration for a family of functions, which corresponds to the Mann iteration with $\lim _{n \rightarrow \infty} \alpha_{n} \neq 0$. We prove convergence results for this iteration when applied to strongly pseudocontractive or strongly accretive maps.

\section{Introduction}

Let $X$ be a real Banach space. The map $J: X \rightarrow 2^{X^{*}}$ given by

$$
J x:=\left\{f \in X^{*}:\langle x, f\rangle=\|x\|^{2},\|f\|=\|x\|\right\}, \quad \forall x \in X,
$$

is called the normalized duality mapping. Let $y \in X$ and $j(y) \in J(y)$; note that $\langle\cdot, j(y)\rangle$ is a Lipschitzian map.

Remark 1.1. The above $J$ satisfies

$$
\langle x, j(y)\rangle \leq\|x\|\|y\|, \quad \forall x \in X, \forall j(y) \in J(y) .
$$

Definition 1.2. Let $B$ be a nonempty subset of $X$. The map $T: B \rightarrow B$ is strongly pseudocontractive if there exist $k \in(0,1)$ and $j(x-y) \in J(x-y)$ such that

$$
\langle T x-T y, j(x-y)\rangle \leq k\|x-y\|^{2}, \quad \forall x, y \in B
$$

A map $S: B \rightarrow B$ is called strongly accretive if there exist $k \in(0,1)$ and $j(x-y) \in J(x-y)$ such that

$$
\langle S x-S y, j(x-y)\rangle \geq k\|x-y\|^{2}, \quad \forall x, y \in B
$$

In (1.3), take $k=1$ to obtain a pseudocontractive map. In (1.4), take $k=0$ to obtain an accretive map. 
Let $B$ be a nonempty and convex subset of $X, T: B \rightarrow B$ and $x_{0}, u_{0} \in B$. The Mann iteration (see [3]) is defined by

$$
u_{n+1}=\left(1-\alpha_{n}\right) u_{n}+\alpha_{n} T u_{n}
$$

The Ishikawa iteration is defined (see [2]) by

$$
\begin{aligned}
x_{n+1} & =\left(1-\alpha_{n}\right) x_{n}+\alpha_{n} T y_{n}, \\
y_{n} & =\left(1-\beta_{n}\right) x_{n}+\beta_{n} T x_{n},
\end{aligned}
$$

where $\left\{\alpha_{n}\right\} \subset(0,1)$ and $\left\{\beta_{n}\right\} \subset[0,1)$.

Let $s \geq 2$ be fixed. Let $T_{i}: B \rightarrow B, 1 \leq i \leq s$, be a family of functions. We consider the following multistep procedure:

$$
\begin{gathered}
x_{n+1}=\left(1-\alpha_{n}\right) x_{n}+\alpha_{n} T_{1} y_{n}^{1}, \\
y_{n}^{i}=\left(1-\beta_{n}^{i}\right) x_{n}+\beta_{n}^{i} T_{i+1} y_{n}^{i+1}, \quad i=1, \ldots, s-2, \\
y_{n}^{s-1}=\left(1-\beta_{n}^{s-1}\right) x_{n}+\beta_{n}^{s-1} T_{s} x_{n} .
\end{gathered}
$$

Let $A, b \in(0,1)$ be fixed. The sequence $\left\{\alpha_{n}\right\} \subset(0,1)$ satisfies

$$
\begin{gathered}
0<A \leq \alpha_{n} \leq b<2(1-k), \quad \forall n \in \mathbb{N}, \\
\left\{\beta_{n}^{i}\right\} \subset[0,1), \quad i=1, \ldots, s-1 .
\end{gathered}
$$

Let $F\left(T_{1}, \ldots, T_{s}\right)$ denote the common fixed points set with respect to $B$ for the family $T_{1}, \ldots, T_{s}$. In this paper, we will prove convergence results for iteration (1.7), for strongly pseudocontractive (accretive) maps when $\left\{\alpha_{n}\right\}$ satisfies (1.8). These results improve the recently obtained results from [6], in which $\left\{\alpha_{n}\right\}$ and $\left\{\beta_{n}\right\}$ converge to zero. We give two numerical examples in which iteration (1.7), when $\left\{\alpha_{n}\right\}$ satisfies (1.8), converges faster as in [6]. Note that, in both cases, iteration (1.7) converges faster than Ishikawa iteration.

Lemma 1.3 [4]. Let $X$ be a real Banach space, and let $J: X \rightarrow 2^{X^{*}}$ be the duality mapping. Then for any given $x, y \in X$,

$$
\|x+y\|^{2} \leq\|x\|^{2}+2\langle y, j(x+y)\rangle, \quad \forall x, y \in X, \forall j(x+y) \in J(x+y) .
$$

LEMMA 1.4 [7]. Let $\left\{a_{n}\right\}$ be a nonnegative sequence which satisfies the inequality

$$
a_{n+1} \leq(1-t) a_{n}+\sigma_{n}
$$

where $t \in(0,1)$ is fixed, $\lim _{n \rightarrow \infty} \sigma_{n}=0$. Then $\lim _{n \rightarrow \infty} a_{n}=0$.

\section{Main result}

Theorem 2.1. Let $s \geq 2$ be fixed, $X$ a real Banach space, and $B$ a nonempty, closed, convex subset of $X$. Let $T_{1}: B \rightarrow B$ be a strongly pseudocontractive operator and $T_{2}, \ldots, T_{s}: B \rightarrow B$, 
with $T_{i}(B)$ bounded for all $1 \leq i \leq s$, such that $F\left(T_{1}, \ldots, T_{s}\right) \neq \varnothing$. If $A, b \in(0,1),\left\{\alpha_{n}\right\} \subset$ $(0,1)$ satisfies (1.8), $x_{0} \in B$, and the following condition is satisfied:

$$
\lim _{n \rightarrow \infty}\left\|T_{1} x_{n+1}-T_{1} y_{n}^{1}\right\|=0,
$$

then iteration (1.7) converges to the unique common fixed point of $T_{1}, \ldots, T_{s}$, which is the unique fixed point of $T_{1}$.

Proof. Any common fixed point of $T_{1}, \ldots, T_{s}$, in particular, is a fixed point of $T_{1}$. However, $T_{1}$ can have at most one fixed point since it is strongly pseudocontractive. Let $x^{*}=F\left(T_{1}, \ldots, T_{s}\right)$. Denote

$$
M=\sup _{n \in \mathbb{N}}\left\{\left\|T_{1} y_{n}^{1}\right\|,\left\|x_{0}\right\|,\left\|x^{*}\right\|\right\} .
$$

Then if we assume $\left\|x_{n}\right\| \leq M$, by

$$
\left\|x_{n+1}\right\| \leq\left(1-\alpha_{n}\right)\left\|x_{n}\right\|+\alpha_{n}\left\|T_{1} y_{n}^{1}\right\| \leq M,
$$

we get $\left\|x_{n+1}\right\| \leq M$.

From (1.2) and (1.10), with

$$
\begin{gathered}
x:=\left(1-\alpha_{n}\right)\left(x_{n}-x^{*}\right), \\
y:=\alpha_{n}\left(T_{1} y_{n}^{1}-T_{1} x^{*}\right), \\
x+y=x_{n+1}-x^{*},
\end{gathered}
$$

we get

$$
\begin{aligned}
\left\|x_{n+1}-x^{*}\right\|^{2}= & \left\|\left(1-\alpha_{n}\right)\left(x_{n}-x^{*}\right)+\alpha_{n}\left(T_{1} y_{n}^{1}-T_{1} x^{*}\right)\right\|^{2} \\
\leq & \left(1-\alpha_{n}\right)^{2}\left\|x_{n}-x^{*}\right\|^{2}+2 \alpha_{n}\left\langle T_{1} y_{n}^{1}-T_{1} x^{*}, j\left(x_{n+1}-x^{*}\right)\right\rangle \\
= & \left(1-\alpha_{n}\right)^{2}\left\|x_{n}-x^{*}\right\|^{2}+2 \alpha_{n}\left\langle T_{1} x_{n+1}-T_{1} x^{*}, j\left(x_{n+1}-x^{*}\right)\right\rangle \\
& +2 \alpha_{n}\left\langle T_{1} y_{n}^{1}-T_{1} x_{n+1}, j\left(x_{n+1}-x^{*}\right)\right\rangle \\
\leq & \left(1-\alpha_{n}\right)^{2}\left\|x_{n}-x^{*}\right\|^{2}+2 \alpha_{n} k\left\|x_{n+1}-x^{*}\right\|^{2} \\
& +2 \alpha_{n}\left\langle T_{1} y_{n}^{1}-T_{1} x_{n+1}, j\left(x_{n+1}-x^{*}\right)\right\rangle \\
\leq & \left(1-\alpha_{n}\right)^{2}\left\|x_{n}-x^{*}\right\|^{2}+2 \alpha_{n} k\left\|x_{n+1}-x^{*}\right\|^{2} \\
& +2 \alpha_{n}\left\|T_{1} y_{n}^{1}-T_{1} x_{n+1}\right\|\left\|x_{n+1}-x^{*}\right\| \\
\leq & \left(1-\alpha_{n}\right)^{2}\left\|x_{n}-x^{*}\right\|^{2}+2 \alpha_{n} k\left\|x_{n+1}-x^{*}\right\|^{2} \\
& +4 \alpha_{n}\left\|T_{1} y_{n}^{1}-T_{1} x_{n+1}\right\| M .
\end{aligned}
$$

Using (1.8), we obtain

$$
\left(1-\alpha_{n}\right)^{2} \leq 1-2 \alpha_{n}+\alpha_{n} b<1-2 \alpha_{n}+\alpha_{n} 2(1-k)=1-2 \alpha_{n} k,
$$


thus,

$$
\left\|x_{n+1}-x^{*}\right\|^{2} \leq \frac{\left(1-\alpha_{n}\right)^{2}}{1-2 \alpha_{n} k}\left\|x_{n}-x^{*}\right\|^{2}+\frac{4 \alpha_{n} M}{1-2 \alpha_{n} k}\left\|T_{1} y_{n}^{1}-T_{1} x_{n+1}\right\| .
$$

The following inequality is satisfied:

$$
\begin{aligned}
\frac{\left(1-\alpha_{n}\right)^{2}}{1-2 \alpha_{n} k} & =\frac{\left(1-\alpha_{n}\right)^{2}\left(1-2 \alpha_{n} k+2 \alpha_{n} k\right)}{1-2 \alpha_{n} k}=\left(1-\alpha_{n}\right)^{2}\left(1+\frac{2 \alpha_{n} k}{1-2 \alpha_{n} k}\right) \\
& =\left(1-\alpha_{n}\right)^{2}+\frac{2 \alpha_{n} k\left(1-\alpha_{n}\right)^{2}}{1-2 \alpha_{n} k} \leq\left(1-\alpha_{n}\right)^{2}+2 \alpha_{n} k \leq 1-2 \alpha_{n}+\alpha_{n} b+2 \alpha_{n} k \\
& =1-(2(1-k)-b) \alpha_{n} \leq 1-(2(1-k)-b) A .
\end{aligned}
$$

Substituting (2.6) and (2.8) into (2.7), we obtain

$$
\left\|x_{n+1}-x^{*}\right\|^{2} \leq(1-(2(1-k)-b) A)\left\|x_{n}-x^{*}\right\|^{2}+\frac{4 b M}{1-2 b k}\left\|T_{1} y_{n}^{1}-T_{1} x_{n+1}\right\| .
$$

Set

$$
\begin{gathered}
a_{n}:=\left\|x_{n}-x^{*}\right\|^{2}, \\
t:=(2(1-k)-b) A \in(0,1), \\
\sigma_{n}:=\frac{4 b M}{1-2 b k}\left\|T_{1} y_{n}^{1}-T_{1} x_{n+1}\right\| .
\end{gathered}
$$

From (2.1), we know that $\lim _{n \rightarrow \infty} \sigma_{n}=0$; all the assumptions of Lemma 1.4 are fulfilled and consequently we have $\lim _{n \rightarrow \infty}\left\|x_{n}-x^{*}\right\|=0$.

In Theorem 2.1, $\left\{\alpha_{n}\right\}$ does not converge to zero, while in [6], $\left\{\alpha_{n}\right\}$ converges to zero.

Theorem 2.2 [6]. Let $s \geq 2$ be fixed, $X$ a real Banach space with a uniformly convex dual, and $B$ a nonempty, closed, convex subset of $X$. Let $T_{1}: B \rightarrow B$ be a strongly pseudocontractive operator and $T_{2}, \ldots, T_{s}: B \rightarrow B$, with $T_{i}(B)$ bounded for all $1 \leq i \leq s$, such that $F\left(T_{1}, \ldots, T_{s}\right) \neq \varnothing$. If $\left\{\alpha_{n}\right\} \subset(0,1)$ satisfies $\lim _{n \rightarrow \infty} \alpha_{n}=0, \sum_{n=1}^{\infty} \alpha_{n}=+\infty$, and $\left\{\beta_{n}^{i}\right\} \subset$ $[0,1), i=1, \ldots, s-1$, satisfy $\lim _{n \rightarrow \infty} \beta_{n}^{1}=0$, then iteration (1.7) converges to a fixed point of $T_{1}, \ldots, T_{s}$.

The Banach space in Theorem 2.1 contains no restrictions.

\section{Further results}

Denote by $I$ the identity map.

Remark 3.1. Let $T, S: X \rightarrow X$ and let $f \in X$ be given. Then,

(i) a fixed point for the map $T x=f+(I-S) x$, for all $x \in X$, is a solution for $S x=f$;

(ii) a fixed point for $T x=f-S x$ is a solution for $x+S x=f$. 
Remark 3.2 [5]. The following are true.

(i) The operator $T: X \rightarrow X$ is a (strongly) pseudocontractive map if and only if ( $I-$ $T): X \rightarrow X$ is (strongly) accretive.

(ii) If $S: X \rightarrow X$ is an accretive map, then $T=f-S: X \rightarrow X$ is a strongly pseudocontractive map.

We consider iteration (1.7), with $T_{i} x=f_{i}+\left(I-S_{i}\right) x, 1 \leq i \leq s$ and $s \geq 2,\left\{\alpha_{n}\right\} \subset(0,1)$, $\left\{\beta_{n}^{i}\right\} \subset[0,1), i=1, \ldots, s-1$ satisfying $(1.8)$ :

$$
\begin{gathered}
x_{n+1}=\left(1-\alpha_{n}\right) x_{n}+\alpha_{n}\left(f_{1}+\left(I-S_{1}\right) y_{n}^{1}\right), \\
y_{n}^{i}=\left(1-\beta_{n}^{i}\right) x_{n}+\beta_{n}^{i}\left(f_{i+1}+\left(I-S_{i+1}\right) y_{n}^{i+1}\right), \quad i=1, \ldots, s-2, \\
y_{n}^{s-1}=\left(1-\beta_{n}^{s-1}\right) x_{n}+\beta_{n}^{s-1}\left(f_{s-1}+\left(I-S_{s}\right) x_{n}\right) .
\end{gathered}
$$

Theorem 2.1, Remark 3.1(i), and Remark 3.2(i) lead to the following result.

Corollary 3.3. Let $s \geq 2$ be fixed, $X$ a real Banach space, and $S_{1}: X \rightarrow X$ a strongly accretive operator, $S_{2}, \ldots, S_{s}: X \rightarrow X$, such that the equations $S_{i} x=f_{i}, 1 \leq i \leq s$, have a common solution and $T_{i}(X), 1 \leq i \leq s$, are bounded. If $A, b \in(0,1),\left\{\alpha_{n}\right\} \subset(0,1)$ satisfies (1.8), and condition (2.1) is satisfied, then iteration (3.1) converges to a common solution of $S_{i} x=f_{i}$, $1 \leq i \leq s$.

We consider iteration (1.7), with $T_{i} x=f_{i}-S_{i} x, 1 \leq i \leq s$, and $s \geq 2,\left\{\alpha_{n}\right\} \subset(0,1)$, $\left\{\beta_{n}^{i}\right\} \subset[0,1), i=1, \ldots, s-1$, satisfying (1.8):

$$
\begin{gathered}
x_{n+1}=\left(1-\alpha_{n}\right) x_{n}+\alpha_{n}\left(f_{1}-S_{1} y_{n}^{1}\right), \\
y_{n}^{i}=\left(1-\beta_{n}^{i}\right) x_{n}+\beta_{n}^{i}\left(f_{i+1}-S_{i+1} y_{n}^{i+1}\right), \quad i=1, \ldots, s-2, \\
y_{n}^{s-1}=\left(1-\beta_{n}^{s-1}\right) x_{n}+\beta_{n}^{s-1}\left(f_{s-1}-S_{s} x_{n}\right) .
\end{gathered}
$$

Theorem 2.1, Remark 3.1(ii), and Remark 3.2(ii) lead to the following result.

Corollary 3.4. Let $s \geq 2$ be fixed, $X$ a real Banach space, and $S_{1}: X \rightarrow X$ an accretive operator, $S_{2}, \ldots, S_{s}: X \rightarrow X$, such that the equations $x+S_{i} x=f_{i}, 1 \leq i \leq s$, have a common solution and $S_{i}(X), 1 \leq i \leq s$, are bounded. If $A, b \in(0,1),\left\{\alpha_{n}\right\} \subset(0,1)$ satisfies (1.8), and condition (2.1) is satisfied, then iteration (3.2) converges to a common solution of $x+S_{i} x=$ $f_{i}, 1 \leq i \leq s$.

\section{Numerical examples}

Let $X=\mathbb{R}^{2}$ be the euclidean plane, consider $x=(a, b) \in \mathbb{R}^{2}$, with $x^{\perp}=(b,-a) \in \mathbb{R}^{2}$. We know that $\left\langle x, x^{\perp}\right\rangle=0,\|x\|=\left\|x^{\perp}\right\|,\left\langle x^{\perp}, y^{\perp}\right\rangle=\langle x, y\rangle,\left\|x^{\perp}-y^{\perp}\right\|=\|x-y\|$, and $\left\langle x^{\perp}, y\right\rangle+\left\langle x, y^{\perp}\right\rangle=0$, for all $x, y \in \mathbb{R}^{2}$. Denote by $B$ the closed unit ball. In [1], we can get the following example in which Ishikawa iteration (1.6) converges and (1.5) is not convergent. 
Table 4.1

\begin{tabular}{lcc}
\hline$\backslash$ Iteration (1.7) & Case 1 & Case 2 \\
\hline Step 10 & $(0.2217,0.1480)$ & $(0.0151,-0.0023)$ \\
Step 15 & $(0.1837,0.1184)$ & $(0.0017,-0.0006)$ \\
Step 20 & $(0.1603,0.1015)$ & $(0.0002,-0.0001)$ \\
Step 21 & $(0.1566,0.0989)$ & $10^{-3} \cdot(0.1156,-0.0686)$ \\
Step 22 & $(0.1531,0.0965)$ & $10^{-4} \cdot(0.7406,-0.4641)$ \\
Step 23 & $(0.1499,0.0942)$ & $10^{-4} \cdot(0.4743,-0.3129)$ \\
Step 24 & $(0.1468,0.0921)$ & $10^{-4} \cdot(0.3037,-0.2103)$ \\
Step 25 & $(0.1440,0.0902)$ & $10^{-4} \cdot(0.1945,-0.1409)$ \\
\hline
\end{tabular}

Example $4.1[1]$. Let $H=\mathbb{R}^{2}$ and let

$$
B_{1}=\left\{x \in \mathbb{R}^{2}:\|x\| \leq \frac{1}{2}\right\}, \quad B_{2}=\left\{x \in \mathbb{R}^{2}: \frac{1}{2} \leq\|x\| \leq 1\right\} .
$$

The map $T: B \rightarrow B$ is given by

$$
T x= \begin{cases}x+x^{\perp}, & x \in B_{1} \\ \frac{x}{\|x\|}-x+x^{\perp}, & x \in B_{2} .\end{cases}
$$

Then the following are true:

(i) $T$ is Lipschitz and pseudocontractive;

(ii) for all $\left(\alpha_{n}\right)_{n} \subset(0,1)$, the Mann iteration does not converge to the fixed point of $T$ (which is the point $(0,0)$ and it is unique).

The main result from [2] assures the convergence of the Ishikawa iteration (1.6) applied to the map $T$ given by (4.2). The convergence is very slow. In [6], for the same $T$, it was shown that iteration (1.7) converges faster. Here, we give an example for which (1.7) with $\left\{\alpha_{n}\right\}$ satisfying (1.8) converges even faster as in [6].

Case 1 [6]. Consider now $T_{1}(x, y)=0.5 \cdot(x, y)$, for all $(x, y) \in B, T_{2}=T$, and $s=2$, where $T$ is given by (4.2), the initial point $x_{0}=(0.5,0.7)$, and $\alpha_{n}=\beta_{n}=1 /(n+1)$ in (1.7). The main result from [6] assures the convergence of (1.7).

Case 2. Consider $T_{1}(x, y)=0.5 \cdot(x, y)$, for all $(x, y) \in B, T_{2}=T$, and $s=2$, where $T$ is given by (4.2), the initial point $x_{0}=(0.5,0.7), \alpha_{n}=0.7$, for all $n \in \mathbb{N}$, and $\beta_{n}=1 /(n+1)$ in (1.7). The fixed point for both functions is $(0,0)$. Observe that $k=0.5$, and $\left\{\alpha_{n}\right\}$ satisfies (1.8):

$$
A=0.7=\alpha_{n}=b \leq 2(1-k)=1, \quad \forall n \in \mathbb{N} .
$$

Note that Mann iteration does not converge for any $\left\{\alpha_{n}\right\} \subset(0,1)$. Using a Matlab program, we obtain Table 4.1.

Case 3. Consider in (1.7) the same $T_{1}, T_{2}, s=2$, and $x_{0}$ as in Case 1 and $\alpha_{n}=\beta_{n}=$ $1 / \sqrt{n+1}$. 
Table 4.2

\begin{tabular}{lccc}
\hline$\backslash$ Iteration & Case 3 $(1.7)$ & Case 4 $(1.7)$ & Ishikawa iteration \\
\hline Step 10 & $(0.0631,-0.0333)$ & $(0.0044,-0.0164)$ & $(0.4545,0.2689)$ \\
Step 15 & $(0.0256,-0.0221)$ & $(-0.0010,-0.0018)$ & $(0.1289,-0.4827)$ \\
Step 20 & $(0.0117,-0.0139)$ & $10^{-5} \cdot(-22.6516,-11.0267)$ & $(-0.4456,-0.1532)$ \\
Step 11 & $(0.0101,-0.0126)$ & $10^{-5} \cdot(-15.5657,-5.4373)$ & $(-0.4651,-0.0274)$ \\
Step 22 & $(0.0087,-0.0115)$ & $10^{-5} \cdot(-10.5234,-2.3727)$ & $(-0.4511,0.0941)$ \\
Step 23 & $(0.0075,-0.0105)$ & $10^{-5} \cdot(-7.0134,-0.7743)$ & $(-0.4077,0.2037)$ \\
Step 24 & $(0.0066,-0.0096)$ & $10^{-5} \cdot(-4.6140,-0.0022)$ & $(-0.3407,0.2954)$ \\
Step 25 & $(0.0057,-0.0088)$ & $10^{-5} \cdot(-2.9993,0.3215)$ & $(-0.2562,0.3654)$ \\
Step 1500 & - & - & $(0.0790,-0.0311)$ \\
\hline
\end{tabular}

Case 4. Consider in (1.7) $T_{1}, T_{2}, s=2$, and $x_{0}$ as above and $\alpha_{n}=0.7$, for all $n \in \mathbb{N}, \beta_{n}=$ $1 / \sqrt{n+1}$.

Also, consider the Ishikawa iteration with the same $T$ as in $(4.2), x_{0}=(0.5,0.7), \alpha_{n}=$ $\beta_{n}=1 / \sqrt{n+1}$, for all $n \in \mathbb{N}$. The main result from [2] assures the convergence of Ishikawa iteration. Note that in this case the convergence is very slow. Eventually, Example 4.1 assures that for the same map, Mann iteration does not converge. A Matlab program leads to the evaluations illustrated in Table 4.2.

\section{Acknowledgment}

The authors are indebted to the referee for carefully reading the paper and for making useful suggestions.

\section{References}

[1] C. E. Chidume and S. A. Mutangadura, An example of the Mann iteration method for Lipschitz pseudocontractions, Proc. Amer. Math. Soc. 129 (2001), no. 8, 2359-2363.

[2] S. Ishikawa, Fixed points by a new iteration method, Proc. Amer. Math. Soc. 44 (1974), no. 1, $147-150$.

[3] W. R. Mann, Mean value methods in iteration, Proc. Amer. Math. Soc. 4 (1953), 506-510.

[4] C. H. Morales and J. S. Jung, Convergence of paths for pseudocontractive mappings in Banach spaces, Proc. Amer. Math. Soc. 128 (2000), no. 11, 3411-3419.

[5] B. E. Rhoades and Ş. M. Şoltuz, The equivalence of Mann iteration and Ishikawa iteration for non-Lipschitzian operators, Int. J. Math. Math. Sci. 2003 (2003), no. 42, 2645-2651.

[6] Mean value iteration for a family of functions, to appear in Nonlinear Funct. Anal. Appl.

[7] Ş. M. Şoltuz, Some sequences supplied by inequalities and their applications, Rev. Anal. Numér. Théor. Approx. 29 (2000), no. 2, 207-212.

B. E. Rhoades: Department of Mathematics, Indiana University, Bloomington, IN 47405-7106, USA

E-mail address: rhoades@indiana.edu

Ştefan M. Şoltuz: Institute of Numerical Analysis, P.O. Box 68-1, 400110 Cluj-Napoca, Romania

E-mail address: smsoltuz@gmail.com 


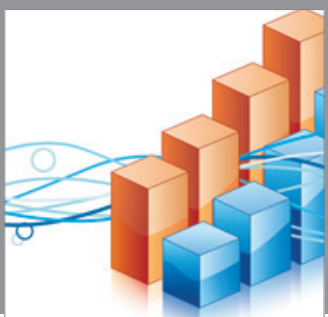

Advances in

Operations Research

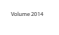

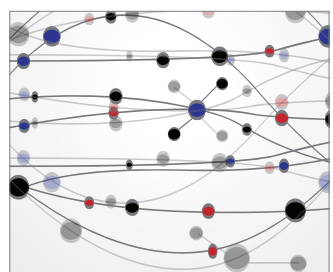

\section{The Scientific} World Journal
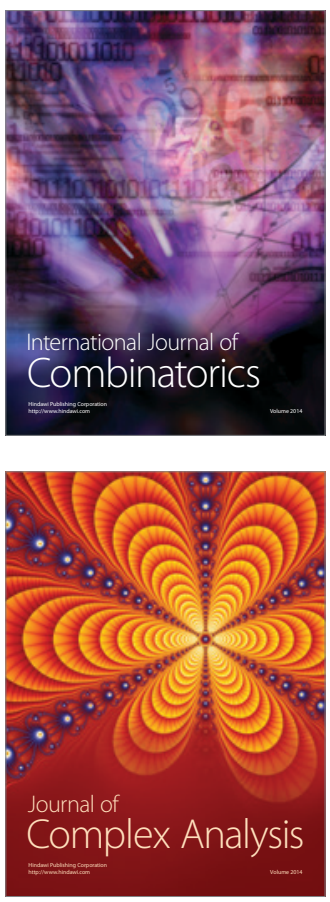

International Journal of

Mathematics and

Mathematical

Sciences
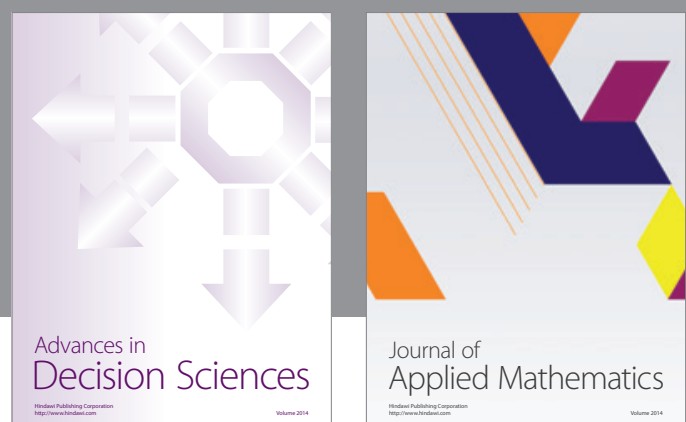

Journal of

Applied Mathematics
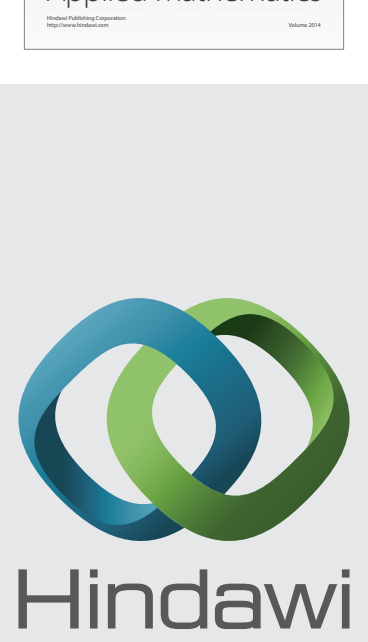

Submit your manuscripts at http://www.hindawi.com
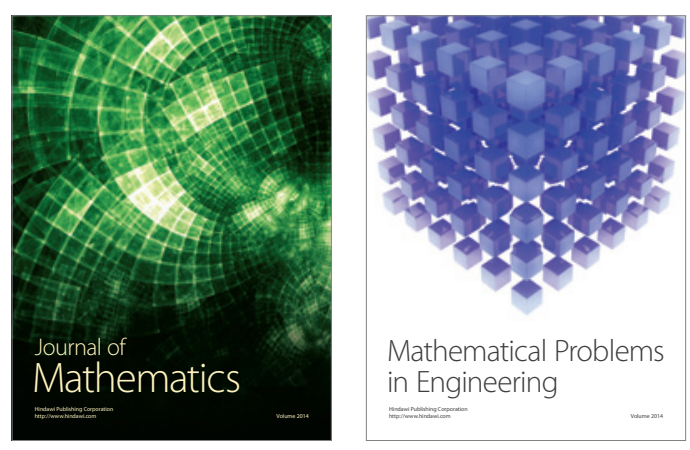

Mathematical Problems in Engineering
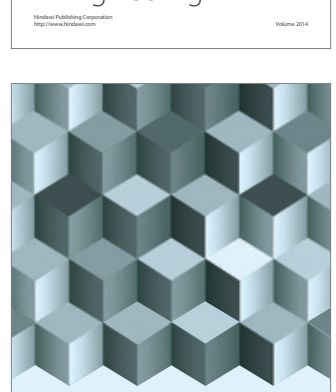

Journal of

Function Spaces
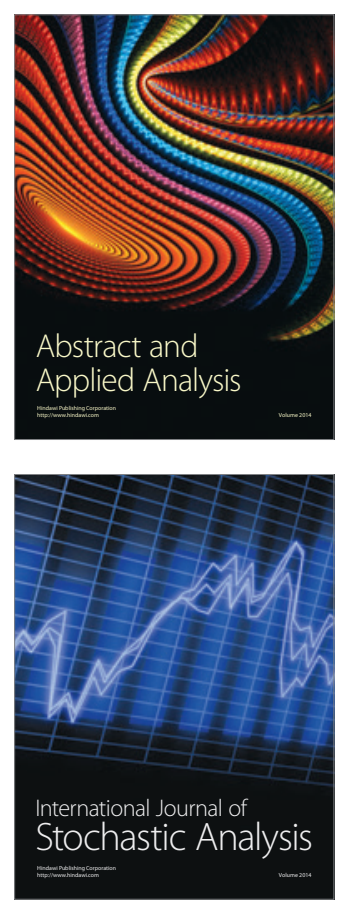

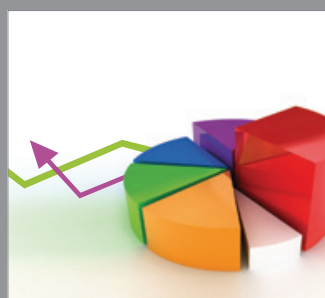

ournal of

Probability and Statistics

Promensencen
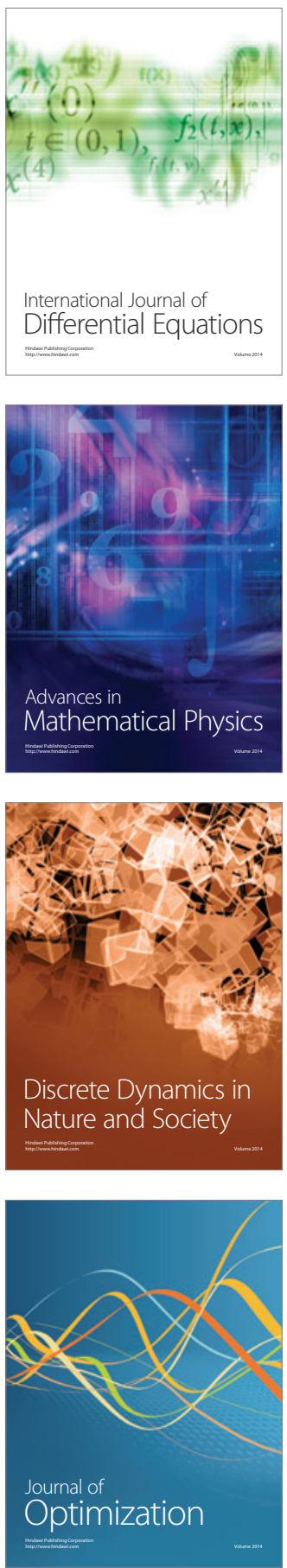